\title{
Correction to: Report of the International Astronomical Union Division I Working Group on Precession and the Ecliptic
}

\author{
J. L. Hilton ${ }^{1,12} \oplus \cdot$ N. Capitaine ${ }^{2}$ J. Chapront ${ }^{2}$ - J. M. Ferrandiz ${ }^{3}$ - A. Fienga ${ }^{4}$. \\ T. Fudushima ${ }^{5}$. J. Getino ${ }^{6}$. P. Mathews ${ }^{7}$. J. -L. Simon ${ }^{4} \cdot$ M. Soffel ${ }^{8}$. J. Vondrak $^{9}$. \\ P. Wallage ${ }^{10} \cdot$ J. Williams ${ }^{11}$
}

Received: 1 December 2020 / Revised: 1 December 2020 / Accepted: 11 December 2020 /

Published online: 18 February 2021

(c) Springer Nature B.V. 2021

\section{Correction to:}

\section{Celestial Mechanics and Dynamical Astronomy (2006) 94:351-367 https://doi.org/10.1007/s10569-006-0001-2}

The relation for $p_{A}$ in Eq. 39 of Capitaine et al. (2003) shows that the coefficient of fifthorder term for the general precession in longitude, $p_{A}$, is $-3.83 \times 10^{-8}$. However, Table 1 of Hilton et al. (2006) gives this coefficient as $+3.83 \times 10^{-8}$. The sign in Capitaine et al. (2003) is correct. At this epoch, J2020.5, the accumulated error amounts to approximately $+2.77 \times 10^{-11} \operatorname{arcsec}$ and is increasing at about $6.8 \times 10^{-12} \operatorname{arcsec}_{\mathrm{yr}^{-1}}$.

Acknowledgements The author would like to thank C. Hohenkerk, the chair of the IAU SOFA Board for pointing out this error in the original publication.

The original article can be found online at https://doi.org/10.1007/s10569-006-0001-2.

J. L. Hilton

james.1.hilton12.civ@mail.mil

1 U.S. Naval Observatory, Washington, DC, USA

2 Observatoire de Paris, Paris, France

3 U. de Alicante, Alicante, Spain

4 Institut de Mécanique Céleste, Paris, France

5 National Astronomical Observatory, Japan, Tokyo, Japan

6 U. de Valladolid, Valladolid, Spain

7 U. of Madras, Chennai, India

8 T. U. Dresden, Dresden, Germany

9 Czech Acad. Sci., Prague, Czech Republic

10 Her Majesty's Nautical Almanac Office, Chilton, Didcot, UK

11 Jet Propulsion Laboratory, Pasadena, CA, USA

121274 Hwy 238, Jacksonville, OR 97530, USA 


\section{References}

Capitaine, N., Wallace, P.T., Chapront, J.: Expressions for IAU 2000 precession quantities. Astron. Astrophys. 412, 567-586 (2003)

Hilton, J.L., Capitaine, N., Chapron, J., Ferrandiz, J.M., Fienga, A., Fukushima, T., Getino, J., Mathews, P., Simon, J.-L., Soffel, M., Vondrak, J., Wallace, P., Williams: Report of the international astronomical union division i working group on precession and the ecliptic. Celest. Mech. Dyn. Astron. 94, 351-367 (2006)

Publisher's Note Springer Nature remains neutral with regard to jurisdictional claims in published maps and institutional affiliations. 